\title{
IT-based Knowledge, Adaptive Behavior and Service Performance Improvement
}

\author{
Zhuo Peng, Yu Wang* \\ School of Economics, Shenzhen Polytechnic, Shenzhen, China \\ Email address: \\ Paulapeng@szpt.edu.cn (Zhuo Peng),Wynne81@szpt.edu.cn (Yu Wang) \\ ${ }^{*}$ Corresponding author
}

To cite this article:

Zhuo Peng, Yu Wang. IT-based Knowledge, Adaptive Behavior and Service Performance Improvement. International Journal of Intelligent Information Systems. Vol. 10, No. 4, 2021, pp. 44-49. doi: 10.11648/j.ijiis.20211004.12

Received: July 26, 2021; Accepted: August 13, 2021; Published: August 24, 2021

\begin{abstract}
The continuing investment in IT applications in business operations by enterprises worldwide has generated interest and research among the academia pertaining to whether and how IT applications can enhance employees work performance. Within such a context, it is the objective of this paper to hypothesize and illustrate how service employees can utilize the IT-based knowledge to improve their service performance and achieve customer satisfaction. A model is developed based upon the literature of categorization and adaptive behavior, conceptualizing a IT-knowledge driven process in which employees categorize customers and adapt to them by modifying service delivery and customizing service options. Five hypotheses are thus proposed within the theoretical framework of this model to justify the causal relationship in-between IT-knowledge and service performance, mediated by employees' adaptive behavior. It is argued in this paper that IT-based knowledge enables employees to assign the prospective customers to customers categories so as to anticipate their expectations and preferences. Accordingly, employees adjust their interpersonal behavior in their interactions with customers and customize service options to customers' preferences. With the introduction of IT-based knowledge as an antecedent to adaptive behavior, this paper enriches the extant literature in IT support for employees performance and offers new insight to business management when motivating their service employees to elevate the level of customer satisfaction with the service quality.
\end{abstract}

Keywords: IT-based Knowledge, Service Performance, Adaptive Behavior, Categorization

\section{Introduction}

There is a continuing investment globally in IT applications like Customer Relationship Management (CRM) and Sales Force Automaton (SFA). The total sales volume of CRM software is now expected to reach more than $\$ 80$ billion by 2025 with SFA reaching $\$ 78$ billion by 2023. Such a heavy expenditure explains the growing concern in academia about what benefits business can reap from such IT applications. Scholars have undertaken intensive research into CRM and SFA from the perspectives of sales, service and information systems. Many of them agree there is a positive connection between IT applications and business performance. CRM can increase the profitability and performance of a company by creating customers satisfaction [13]. CRM gives service organizations a competitive advantage through its management of customer information or knowledge [25].
Dous et al. [12] differentiates CRM knowledge into knowledge for, from and about customers. They conducted three case studies which provide evidence for the suggestion that CRM knowledge is supportive of such positive performance outcomes as optimized service quality, higher levels of customer satisfaction and marketing campaign success. Following such rationalizations, this paper proposes that IT-based knowledge, i.e., customer information gathered and managed via IT applications has a positive impact on business performance. This also raises a concern about how IT-based knowledge is utilized by the frontline employees in the process of selling products and offering services to the customers. Ahearne et al. [1, 2] argued that salespeople are both knowledgeable and adaptable in dealing with customers' various demands through their use of sales technology applications such as 
SFA. Chen et al. [8] conducted a survey with over 200 frontline employees in a financial institution and concluded that employees demonstrate adaptive behavior in service encounters, which in turn enhances their service performance because CRM systems enables them to assess customers information. Previous studies have attested that, with the aid of IT-based knowledge, employees are able to accommodate customers in line with their various expectations and demands, since there is no best way of satisfying all kinds of customers [29]. What is absent in their studies, however, is there is no direct investigation in how IT-based knowledge is tapped into and internalized by frontline employees when applying such knowledge in dealing with customers. Therefore, it is our goal to conceptualize and elaborate this process.

This paper looks closely at the process and the mechanisms frontline employees experience in their adaptive behavior by developing a conceptual model using "IT-based Knowledge", "Adaptive Behavior" and "Service Performance" as key constructs. Theoretically, such a conceptualization can enrich the extant literature in the domain of IT-support for employees performance, as IT-based knowledge is introduced as an antecedent to employees' adaptive behavior at work. Another motivation for the theorization comes from an inquiry about the service quality perceived by the customers when frontline employees utilize IT-based knowledge. This will generate some empirical findings in respect to making improvements in service performance of frontline employees via the support from IT applications.

The theoretical foundation in this paper is the concept of categorization. Categorization is a well-accepted human cognitive mechanism, in which people "simplify perceptions of complex social stimuli by grouping or classifying people and their behaviors into already existing, contextually meaningful categories" [5]. Categorization is the ability to group newly encountered others in existing categories based on past experience. Through the process of categorization, people can predict the behavior of the newly encountered and respond accordingly [5]. Categorization is used to explain the adaptive behavior of knowledgeable salespeople who are capable of retrieving information from previous categories and deploy them on new customers [29]. In line with extant studies, it is argued in this paper that service employees categorize their customers by comparing the new customers with the previous ones, whose information is collected via IT applications such as CRM or SFA. Categorizing enables employees to demonstrate adaptive behaviors to accommodate the prospective customers, thus creating strong performance in service encounters.

Thus, the objective of this paper is to hypothesize an IT-driven process that employees undergo when they employ knowledge from IT applications in serving customers, which can exemplify how IT-support strengthens work performance. Following the introduction, the paper proceeds with a literature review. Then a conceptual model is developed and five hypotheses are elaborated. Lastly, the paper concludes with theoretical as well as managerial implications.

\section{Literature Review}

\subsection{Service Performance}

Service performance is part of service employees' job performance. Motowidlo and Kell [23] define job performance as "behaviors that can make a difference to organizational goal accomplishment ". In service businesses, such as banking, medical and legislative companies, it is a common goal to maintain a high level of service quality, because service quality is antecedent to customer satisfaction and to customer purchase intention towards the service provider [26]. Creating a high level of service quality is pivotal to business success because it contributes to high levels of customer satisfaction, which can generate economic benefits for the service organization [18]. Service quality is perceived and evaluated by customers through two dimensions, service delivery process and service outcome. Service delivery process describes the way in which services are handled by employees whereas service outcome refers to what option is offered to the customers in the service encounter [6]. Based on these arguments, this paper interprets service performance as employees' behaviors that affect the levels of service quality in two aspects i.e., how employees interact with their customers in delivering the service and what options employees offer to the customers as the service outcome.

\subsection{IT-based Knowledge}

IT applications such as Customer Relationship Management (CRM) and Sales Force Automation (SFA) are often mandatory for employees to use to assist them in sales or service operations. Employees can demonstrate a higher level of knowledge by tapping into the available information stored in such IT applications [2]. SFA automates the daily activities for salespeople and offers the salespeople customer account information and transaction history [1, 7]. CRM generates three types of customer-related knowledge for organizations: knowledge for the customers, knowledge about the customers and knowledge from the customers $[11,16]$. In line with previous investigations into knowledge via CRM and SFA, IT-based knowledge is defined as customer-related information accessed from these IT applications which can be directly deployed by employees in their work tasks. IT-based knowledge entails knowledge for the customers, e.g., information about product, suppliers and market [15]; knowledge about the customers, e.g. customer profile, histories, purchasing activity, financial capability, needs and requirements [11]. "Knowledge from customers" is excluded from IT-based knowledge in this paper because such knowledge is "incorporated by the company for product and service innovation, idea generation as well as for the continuous improvement of its products and services" [12]. Such knowledge from customers is utilized more at the organizational level than at the individual level.

\subsection{Knowledge Adoption}

Many studies in the field of knowledge management have demonstrated that employees are prone to exploit existing 
knowledge from their company and their access to such knowledge affects work performance positively [10,32]. When knowledge is collected and and transferred from the company to employees, it is adopted by them for the sake of work efficiency [33]. Min [22] hypothesized that different types of knowledge can be gained from different usage of knowledge management systems (KMS). Knowledge generated to support day-to-day operations at work will be adopted by individual employees because it adds immediate value to their daily work. In other words, knowledge has the potential to make a strong and immediate contribution to work performance. Despite the lack of studies on knowledge adoption in sales and service practices [9], this paper follows the stream of research in knowledge management and conceptualize knowledge adoption as exploiting extant knowledge from IT applications such as CRM in daily operations for the sake of work effectiveness at the level of an individual employee.

\subsection{Adaptive Behavior}

Adaptive behavior occurs when an individual alters his or her behavior in response to a new task or new situation [19]. There are three streams of research on employees' adaptive behavior in the work context that are relevant to the current study:

(1) Adaptive selling improves salespeople's outcome performance and enhances customers' evaluation of the service and products from salespeople [27, 29].

(2) Service employees adapt to customers' needs and requirements in two ways. Firstly, they modify their behavior in the service delivery process. Secondly, they customize the service offering to satisfy customers [17]. This employee adaptiveness in service encounters is referred to as "interaction personalization" "transaction outcome personalization" [31] "interpersonal adaptive behavior" and "service-offering adaptive behavior" [17].

(3) Constraints of Adaptive Behavior: Employees' adaptive behavior is variable and subject to their knowledge, experience, personality, and idiosyncrasies [17]. Employees with access to customer information via CRM or SFA are more likely to practice adaptive behavior [17, 27].

Grounded on previous theories, it is concluded that adaptive behavior in service encounters comprises employees' behavioral adjustment and customizing service options for the purpose of catering to customers' needs and requirements. Adaptive behavior is positively related to employees' work performance and it can be used as a bridge linking IT-based knowledge adoption and service performance in the conceptualization.

\section{Conceptualizing and Model Development}

\subsection{Categorization Theory}

"Categorization is a ubiquitous process that plays out across a wide variety of contexts" [34]. In cognitive psychology, many scholars agree that for people to function in a complex environment, they usually generalize things and people around them and assign them to already familiar groups [21]. The key benefit of categorizing is that people can process vast amounts of intricate information quickly and efficiently so to predict and prepare for the behaviors from a new member assigned to an existing category, even though category boundaries are not always clear-cut [34].

In personal selling, categorizing customers is a prerequisite for adaptive selling behavior. Categorizing customers enables salespeople to practice different strategies on different customers [29]. As noted by Román and Iacobucci (2010), while salespeople highlight product value when dealing with price-sensitive customers, they emphasize product benefits when selling to a low-tech customer. It is evident that categorizing customers also applies to employees interacting with their customers in a service encounter. When a service employee approaches a prospective customer, the employee relies on the cues of the customer category to predict the expectations and behaviors of the particular customer who is similar with other customers in the same category. Categorizing customers in service encounters can assist in an employee's understanding of prospective customers, which enables the employee to know how to serve and what to serve in the service encounter.

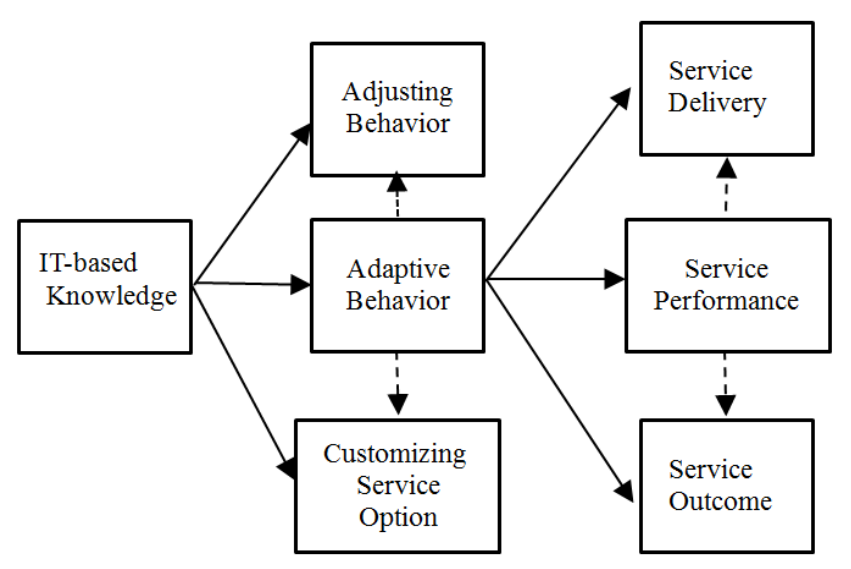

Figure 1. Conceptualizing Framework.

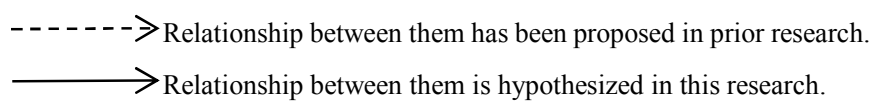

\subsection{Conceptualizing and Hypothesizing}

Within the theoretical framework of categorization, a model can be constructed to conceptualize how IT-based knowledge adoption contributes to employees' strong performance in service encounters. When IT-based knowledge is made available through such applications as CRM and SFA, it is conducive to customer categorization. Customer categorization assists service employees in their behavioral adjustment in the interaction with prospective customers as well as in customizing service options for the customers' choice. Such adaptive behavior is expected to 
positively influence customers' perceptions and evaluations of service quality, the core of work performance in the service context. Figure 1 is an illustration of our model with key constructs in boxes, i.e., "IT-based Knowledge", "Adaptive Behavior" and "Service Performance". Five hypotheses will be developed. Hypothesis 1 explains the inter-relatedness between IT-based knowledge and adaptive behavior through categorizing customers. Hypotheses $2 \mathrm{a}$ and $2 \mathrm{~b}$ are posited to elaborate two dimensions of adaption to customers through IT-knowledge adoption. Hypotheses 3 and 4 are developed to justify the impact of adaptive behavior on employees service performance.

\subsubsection{Adaptive Behavior Initiated by IT-based Knowledge}

When an employee retrieves customer-related knowledge, the process of classifying customers begins on his or her cognitive level of processing information. The initial means of classifying customers are through referral cues, such as age, family size, and type of employment [14]. For instance, customers can be grouped into "need/product based" and "price/promotion conscious" in retail business [30]; meanwhile, there are "advanced age" and "younger prospect" in financial services [14]. As defined in this paper, IT-based knowledge entails knowledge for the customers and knowledge about the customers. Thus an employee is capable of conceptualizing customer categories upon the retrieved "knowledge about the customers", from IT applications such as CRM, which "encompasses the customer's present needs and requirements, future desires, connections, purchasing activity and financial capability." [12]. Customer categories contingent upon IT-based knowledge will also delimit the prospective customer type that an employee can identify and assign to in a service encounter. This is driven by the categorizing mechanism of adding new acquaintances to familiar groups in order to minimize the cognitive effort in a new set of circumstances.

Based on the above argument, we propose that IT-based knowledge is an antecedent to service employees' adaptive behavior. IT-based knowledge assists service employees in categorizing customers. Customer categorization prepares the employees for their adaptation to the prospects in new service encounters. We thus hypothesize:

H1. IT-based knowledge initiates adaptive behavior by customer categorization.

\subsubsection{Adapting to Customers by Adopting IT-based Knowledge}

Customer knowledge generated from KMS is suitable for employees to adopt because it helps with their daily operations [22]. A key difference for services, as opposed to physical products, is the inseparable nature of service, i.e., services are usually produced and consumed at the same time [3]. This suggests IT-based customer knowledge, when adopted by employees in service encounters, can function in two ways: "knowledge about the customer" is deployed when delivering the service for the customers and "knowledge for the customer" (information about product, suppliers and market) is deployed to influence customers to accept the service options.
Regarding adaptive behavior in service encounters, Gwinner et al. (2005) asserted that service employees can adapt to customers' needs by modifying their interpersonal behavior and by modifying the service offering to the customers. Interpersonal behavior includes the wording, the style and the content of employees' communication with the customers, e.g, a repeat customer doesn't need background information about a product in the same way as a new customer [29]. Service offering refers to a set of "predetermined alternatives" which employees can screen for their customers, e.g. a financial adviser with a list of investment choices [20].

With IT-based knowledge adopted and driven by the categorization mechanism, it is believed that a service employee will place a prospective customer in an existing customer category formulated via IT-based knowledge. As a result, the service employee can anticipate the needs and expectations of the categorized customer, which helps the employee to adapt by adopting "knowledge about the customers" in service delivery process and "knowledge for the customers" to elicit service outcome. The adaption evolves through two dimensions: adjusting interpersonal behavior and customizing service options for the prospective customer. We thus hypothesize:

H2a Adoption of IT-based knowledge contributes to interpersonal behavior adjustment.

$\mathrm{H} 2 \mathrm{~b}$ Adoption of IT-based knowledge contributes to service option customization.

\subsubsection{Adaptive Behavior's Impact on Service Performance}

In adaptive selling, salespeople's adaptive behavior contributes to a strong sales performance [28]. It also increases customer satisfaction with the salespeople in the customer-employee interaction experience [28]. In service encounters, employees can customize their service to individual customers through adaptive behavior [31]. Service customization is conducive to a high level of customer satisfaction in service encounters [4]. These findings lead us to conclude that employees' adaptive behavior is positively related to their strong performance at work. Service performance, therefore, as one kind of job performance, is positively affected by adaptive behavior.

As is clarified in the literature review, service quality constitutes the core of performance for employees in service encounters. It is agreed in the service literature that service quality is measured by customers' perception and expectation in their service experience [24]. Perception refers to how customers feel about the customer-employee interaction. Expectation means what customers believe service providers should offer. Therefore, it is proposed that employees' adaptive behavior has a dual impact on perceived service quality: in the service delivery process and in the outcome of the service encounter. In the former case, employees can adjust their interpersonal behavior so to create a satisfying experience for the customers. In the latter case, employees can customize service alternatives so to suit customers' needs better. We thus argue: 
H3 Behavior adjustment positively affects service quality in service delivery process.

H4 Service options customization positively affects service quality of the service outcome.

\section{Conclusion}

A model is constructed to bridge the gap between IT-based knowledge and service employees performance through adaptive behavior within the theoretical framework of categorization. It provides insights into the relatedness between technology use and employees job performance. It goes beyond technology adoption and taps into the cognitive mechanism that lies behind employees' behavior at work. This research indicates a positive relationship between adopting knowledge from IT applications in service encounters and employees job performance. It also offers some guidance for service businesses aiming at a high level of profitability through a high level of service quality. As customers perceive quality directly through service encounters, it is necessary to gear up employees with customer related knowledge via IT applications and communicate the value and usage of such knowledge to them through service training. In service business, there is also a continuous shift from a one-size-fits-all service to customized service for individual customers. Many businesses are keen on tailoring their offerings to the market and upgrading IT to optimize customer relationships. Employees are the key actors to follow through these strategies and innovations targeted at customers' changing needs. Therefore service employees should be encouraged to adapt to customers' preferences based on generic knowledge about customers collected via IT applications.

\section{References}

[1] Ahearne, M., Jelinek, R. and Rapp, A. (2004). Moving Beyond the Direct Effect of SFA Adoption on Salesperson Performance: Training and Support as Key Moderating Factors. Industrial Marketing Management, 34 (4), 379388.

[2] Ahearne, M., Jones, E., Rapp, A. and Mathieu, J. (2008). High Touch through High Tech: The Impact of Salesperson Technology Usage on Sales Performance via Mediating Mechanisms. Management Science, 54 (4), 671-685.

[3] Benoit, S. (2010). Characteristics of Services - a New Approach Uncovers Their Value. Journal of Services Marketing, 24 (5), 359-368.

[4] Bettencourt, L. A. and Gwinner, K. (1996). Customization of the Service Experience: The Role of the Frontline Employee. International Journal of Service Industry Management, 7 (2), $3-20$.

[5] Binning, J. F., Zaba, A. J. and Whattam, J. C. (1986). Explaining the Biasing Effects of Performance Cues in Terms of Cognitive Categorization. The Academy of Management Journal, 29 (3), 521-535.
[6] Brady, M. K. and Cronin, J. (2001). Some New Thoughts on Conceptualizing Perceived Service Quality: A Hierarchical Approach. Journal of Marketing, 65 (3), 34-49.

[7] Cascio, R., Mariadoss, B. J. and Mouri, N. (2009). The Impact of Management Commitment Alignment on Salespersons' Adoption of Sales Force Automation Technologies: An Empirical Investigation. Industrial Marketing Management 39 (7), 1088-1096.

[8] Chen, R., Ou, X., Wang, W., Peng, Z. and Davison, R. M. (2020). Moving Beyond the Direct Impact of Using CRM Systems on Frontline Employees' Service Performance: The Mediating Role of Adaptive Behaviour. Information Systems Journal, 30 (3), 458-491.

[9] Chirawattanakij, S. and Vathanophas, V. (2015). Knowledge Adoption: The influential Factors in the Process. Business Information Review, 32 (3), 158-167.

[10] Cross, R., and Cummings, J. N. (2004). Tie and Network Correlates of Individual Performance in Knowledge Intensive Work. Academy of Management Journal, 47 (6), 928-937.

[11] Davenport, T. H., Harris, J. G. and Kohli, A. K. (2001). How Do They Know Their Customers So Well?. MIT Sloan Management Review, 42 (2), 63-73.

[12] Dous, M., Salomann, H., Kolbe, L. and Brenner, W. (2005). Knowledge Management Capabilities in CRM: Making Knowledge For, From and About Customers Work. Proceedings of the Eleventh Americas Conference on Information Systems, N. Romano (ed), Omaha, NE, USA, 167-178.

[13] ElKordy, M. (2014). The Impact of CRM Capability Dimensions on Organizational Performance. European Journal of Business and Social Sciences, 10 (2), 128-146.

[14] Evans, K. R., Kleine, R. E. III, Landry, T. D. and Crosby, L. A. (2000). How First Impressions of a Customer Impact Effectiveness in an Initial Sales Encounter. Journal of the Academy of Marketing Science, 28 (4), 512-526.

[15] Garcia-Murillo, M. and Annabi, H. (2002). Customer Knowledge Management. Journal of the Operational Research Society, 53 (8), 875-884.

[16] Gebert, H., Geib, M., Kolbe, L. M. and Brenner, W. (2003). Knowledge-enabled Customer Relationship Management. Journal of Knowledge Management, 7 (5), 107-123.

[17] Gwinner, K. P., Bitner, M. J., Brown, S. W. and Kumar, A. (2005). Service Customization through Employee Adaptiveness. Journal of Service Research, 8 (2), 131-148.

[18] Hsieh, J. J. Po-An., Rai, A., Petter, S. and Zhang, T. (2012). Impact of User Satisfaction with Mandated CRM Use on Employee Service Quality. MIS Quarterly, 36 (4), 1065-1080.

[19] Huang, J. L., Ryan, A. M., Zabel, K. L. and Palmer, A. (2014). Personality and Adaptive Performance at Work: A Meta-analytic Investigation. Journal of Applied Psychology. 99 (1), 162-179.

[20] Kelley, S. W. (1992). Developing Customer Orientation among Service Employees. Journal of the Academy of Marketing Science, 20 (1), 27-36.

[21] McGarty, C. (1999). Categorization in Social Psychology, Thousand Oaks, United States: SAGE Publications Inc. 
[22] Min, J., Lee, J., Ryu, S. and Lee, H. (2014). Individuals' Interaction with Organizational Knowledge under Innovative and Affective Team Climates: A Multilevel Approach to Knowledge Adoption and Transformation. Proceedings of the 47th Hawaii International Conference on System Sciences. IEEE Computer Society, USA.

[23] Motowidlo, S. J. and Kell, H. J. (2012). Job performance in; Schmitt, N. W. and Highhouse, S. (Eds) Handbook of psychology, vol. 12: Industrial and organizational psychology, 2nd Edition, Chichester: Wiley, 82-103.

[24] Purcărea V. L., Gheorghe, I. R. and Petrescu, C. M. (2013). The Assessment of Perceived Service Quality of Public Health Care Services in Romania Using the SERVQUAL Scale. Procedia Economics and Finance, 6, 573-585.

[25] Ramesh, K. (2014). Role of Customer Relationship Management in Indian Banking System. International Journal of Applied Services Marketing Perspectives, 4 (2), 645-650.

[26] Rao, K. R. M. (2011). Services Marketing (2nd ed.), New Delhi, India: Dorling Kindersley.

[27] Rapp, A., Agnihotri, R., and Forbes, L. P. (2008). The Sales Force Technology-Performance Chain: The Role of Adaptive Selling and Effort. Journal of Personal Selling \& Sales Management, 28 (4), 335-350.

[28] Robinson, L., Jr., Marshall, G. W., Moncrief, W. C. and Lassk, F. G. (2002). Toward a Shortened Measure of Adaptive Selling. Journal of Personal Selling \& Sales Management, 22 (2), 111-119.
[29] Román, S. and Iacobucci, D. (2010). Antecedents and Consequences of Adaptive Selling Confidence and Behavior: A dyadic Analysis of Salespeople and Their Customers. Journal of the Academy of Marketing Science, 38 (3), 363382 .

[30] Sharma, A. and Levy, M. (1995). Categorization of Customers by Retail Salespeople. Journal of Retailing, 71 (1), 71-81.

[31] Shen, A. and Ball, D. (2009). Is Personalization of Services Always a Good Thing? Exploring the Role of Technology-mediated Personalization (TMP) in Service Relationships. Journal of Services Marketing, 23 (2), 80-92.

[32] Teigland, R. and Wasko, M. M. (2003). Integrating Knowledge through Information Trading: Examining the Relationship between Boundary Spanning Communication and Individual Performance. Decision Sciences, 34 (2), 261-286.

[33] Teigland, R. and Wasko, M. M. (2009). Knowledge Transfer in MNCs: Examining How Intrinsic Motivations and Knowledge Sourcing Impact Individual Centrality and Performance. Journal of International management, 15 (1), 15-31.

[34] Vergne, J. P. and Wry, T. (2014). Categorizing Categorization Research: Review, Integration, and Future Directions. Journal of Management Studies, 51 (1), 56-94. 